\title{
MARKETING DEL SIGLO XXI
}

\section{GENERALIDADES}

La orientación hacia el mercado conocido como marketing se convirtió en la filosofía básica de la empresa estadounidense durante los años 50 y 60 del siglo pasado.

Los cambios importantes producidos en los años 70 y 80 del mismo siglo, tanto en lo económico, social, ambiental y político, plantearon nuevos problemas y retos a la comunidad empresarial, lo que ha obligado a cambiar el concepto original de marketing de satisfacción de necesidades de los clientes, la realización de la tarea de conversión de una corriente of flujos de bienes y servicios en flujo monetario, en ese intercambio o dialéctica permanente entre el productor $y$ el mercado (entorno). El proceso comienza por la identificación de las necesidades, deseos y preferencias del usuario o consumidor lo que a su vez, determinará qué bienes y servicios deberán ofrecer la empresa.

A medida que iba avanzando el significado de marketing surgió la idea de que los mercados no existen para atender las necesidades de las empresas, sino la de los clientes. En consecuencia, el marketing se concibe como una respuesta a una sociedad cada vez más exigente.

Philip Kotler, el gurú del marketing moderno, estuvo en Lima en julio de 1999 gracias a la empresa SEMINARIUM. En esa oportunidad, dijo "que el mercado del futuro va a ser muy diferente al actual, debido al creciente poder de los minoristas masivos, como el caso de los supermercados, el rápido crecimiento de compras desde el hogar, la aparición de nuevos medios de comunicación; la fragmentación y personalización del mercado; la aparición y vigencia de los services o subcontratos; y el surgimiento de nuevos esquemas que crean lealtad de los clientes".

El marketing de este siglo no será privilegio de las grandes empresas, las pequeñas y medianas tendrán su espacio, gracias a la creatividad de quienes las dirigen. Además, el futuro de negocios estará a cargo de pequeñas y medianas empresas, como dice Peter Drucker en su libro "La Sociedad Post Capitalista" porque el ciclo de vida de las grandes corporaciones internacionales (dinosaurios) ya habría llegado a su fase final y serán reemplazados por empresas de menor tamaño, ágiles, flexibles, diligentes, competitivas, innovadoras y eficientes.

Asimismo, la aparición de la empresa virtual, que tan sólo con un fax, una computadora, o un celular podrá participar de forma activa en el mercado, sin inversiones en activos y con costos fijos prácticamente nulos.

Las estrategias en el futuro serán crear lealtad en los clientes a través de servicios que ayuden a resolver sus problemas, a 
atender el negocio de los clientes y de los clientes de sus clientes (CADENA DE VALOR DE LOS PROVEEDORES); es decir, crear más valor para el cliente.

Hoy en día la primera línea de defensa de marketing es la retención de los clientes; la segunda, el punto intermedio entre retener y captar nuevos clientes, es decir recuperar los antiguos; y la tercera, la atracción y captación de nuevos clientes.

Uno de los instrumentos más eficaces para hacer un seguimiento del desempeño de una empresa es medir la satisfacción del cliente. Por eso, es necesario identificar cuál es la satisfacción de los clientes respecto a cada uno de los componentes del negocio, como la calidad del producto, el servicio de entrega, o la rapidez de respuesta cuando se requiere hacer una reparación.

Kotler insiste que lo importante es ganar clientes sin perder lo que tenemos. El costo de obtener nuevos clientes es alto y creciente, los nuevos clientes permanecen cada vez por tiempos más cortos.

La satisfacción del cliente no es suficiente para asegurar su lealtad, los clientes leales son los más rentables y esta lealtad puede ser sistemáticamente fortalecida.

\section{CLAVE PARA CONSEGUIR CLIENTES LEALES}

Una forma acertada para conseguir la fidelidad de los clientes es construir una buena base de datos de los clientes; es decir, conocer su historia, antecedentes y hasta de sus gustos personales. No olvidarse de fechas claves como su onomástico, así logrará una comunicación interactiva con él y desarrollará dispositivos de amarre.
Cada vez el consumidor exige mayor calidad de productos y a bajo precio, a lo que debemos responder con estrategias de mayor valor "más por más", "más por lo mismo", "lo mismo por lo menos".

Por otro lado, los clientes no quieren de lo mismo, sino algo diferente, o con un valor agregado.

Es importante también resaltar lo que Philip Kotler denomina "El fin del mundo físico" donde afirma que ya no es necesario que una empresa ocupe mucho espacio, ya que esto puede ser virtual y encontrarse en cualquier parte.

Los mensajes se hacen en tiempo real a través del correo electrónico e internet; es posible mover objetos en forma de bits en vez de átomos.

Si insistimos en el tema de satisfacción plena y lealtad de nuestros clientes también tenemos que pensar en la innovación, la diferenciación y el desarrollo de nuevos productos. Indudablemente es un proceso complejo que no podemos dejar sólo al Departamento de Investigación y Desarrollo (I +D) sino que debe ser manejado por un equipo multidisciplinario.

Otro factor indispensable es la etapa del procesamiento de los pedidos. Las empresas deben salir de su lentitud. Por ejemplo, la IBM tardaba seis días para aprobar la propuesta de un pedido de un cliente potencial; después de aplicar la reingeniería, el tiempo se redujo a sólo a una hora y veinte minutos. Hay algo muy importante que subrayar, ayer primaba la producción y si era masiva mejor porque permitía economías de escala; hoy manda el consumidor, ya sea final o intermedio y espera ser tratado individualmente. Además, tiene una ventaja ante los vendedores 
tradicionales debido a la mayor información sobre productos y servicios disponibles.

En el proceso tradicional se fabricaba productos masivos para mercados masivos. Para satisfacer las demandas de los clientes actuales, se necesita múltiples versiones del mismo proceso para distintos consumidores y mercados.

Ayer, la administración se centraba en conceptos como planear, dirigir, coordinar y liderar; conceptos no relacionados con el cliente. Hoy la administración está focalizado en la satisfacción del cliente. Este es el centro de nuestro accionar y puede cambiar en cualquier momento si piensa que no recibe una adecuada atención. Para T. Bendell y $R$. Penson el cliente no es rey; sino, la única razón de nuestro negocio. En Japón el cliente no es rey, sino Dios.

\section{EL TRABAJO EN RED}

En este siglo que acaba de iniciarse habrá muchos cambios buenos y malos. Algunas profesiones irán extinguiéndose con la llegada del trabajo en red, como dice el experto en la "hora de la estrategia" Keniche Ohmae. El mencionado pensador se atreve en citar como ejemplo, la profesión de contadores, que desde ahora se ve afectado seriamente debido a la disponibilidad de paquetes de software para muchas operaciones.

De la misma manera, los distribuidores y compradores de bienes para venderlos; es decir, los intermediarios, están en peligro de extinción ya que ahora todo se puede comprar directamente del productor vía internet (venta virtual) sin tener que pagar altos márgenes a los vendedores. Increíblemente, también los médicos de cabecera serán sustituidos por consultas on line, lo mismo sucederá con los profesores, que tendrán una enseñanza más atractiva y realista.
El otro ejemplo que ilustra la extinción de las profesiones podría ser el de traductores; pues aparecerán en el mercado equipos de software que identifiquen, lean y traduzcan documentos en distintos idiomas. Esta tecnología será de uso común en la primera década de este siglo y permitirá el reconocimiento de la voz de las personas.

La era del conocimiento que estamos viviendo plantea el peligro de la obsolescencia del ser humano sino éste no se actualiza; pues los conocimientos se están duplicando cada 18 meses. En la década de 2020 el conocimiento se duplicará cada 3 meses, es decir, estamos hablando del "analfabetismo tecnológico". El hombre requiere permanente actualización, acorde a los nuevos avances científicos y tecnológicos.

Las corporaciones han cambiado su forma de organización de tipo piramidal, formulado por Adam Smith hace 200 años, para adoptar las formas chatas (horizontal), con costos fijos mínimos. Actualmente, está tomando mucho auge los trabajos en redes, conforme sostiene Keniche Ohmae.

El trabajo en red significa que la empresa trabaje en forma estratégica con compañías más pequeñas como ocurre en Japón con Toyota, que encarga a pequeñas y medianas empresas la fabricación del $75 \%$ de componentes del vehículo y sólo el $25 \%$ la elabora la propia empresa.

\section{EL FUTURO IMPREDECIBLE}

Peter Drucker en su libro "El gran poder de las pequeñas ideas" nos dice "el futuro no puede ser conocido; la única cosa cierta acerca de él es que será diferente, más que una continuación del presente. El futuro es como un no nacido aún, amorfo, indeterminado". Que puede ser planeado mediante 
la acción premeditada; y lo único que puede motivar eficazmente esa acción es una idea -una idea de una economía diferente"-.

De la lectura de esta obra se desprende que una pequeña empresa que hace un buen trabajo planeando el futuro, no seguirá siendo "pequeña" por mucho tiempo, pues toda gran empresa exitosa de hoy, alguna vez fue empresa pequeña basado en una idea de lo que debería ser el futuro, tenemos el caso de la XEROX, IBM, entre otros.

Pero ¿qué cambios importantes en la economía, el mercado o el conocimiento nos permitiría conducir a la empresa hacia la obtención de resultados esperados?

En la sociedad post capitalista que ya vivimos, el economista John Kenneth Galbraight sostiene que el dinero es el combustible de la sociedad industrial, pero en la nueva sociedad de la información el combustible es el conocimiento, calificado por Drucker como la "era del conocimiento".

Alvin Toffler afirma que ha nacido un nuevo sistema para crear riqueza, el cual no se basa ya en la fuerza, sino en la mente.

Las tareas relacionadas con la informática, la electrónica, las comunicaciones, la robótica, la biotecnología y la energía se desarrollarán y especializarán cada vez más y como consecuencia de esos cambios se espera en el futuro la aparición de nuevos oficios y profesiones.

El Semanario francés L' Express consultó a expertos para efectuar una previsión sobre las profesiones más allá del año 2000 y concluyó que en el siglo XXI la cuarta parte de población activa de Francia estará empleada en trabajos que aún no existen.

Conforme afirma Drucker el futuro es impredecible; pero, sin embargo, algunos futurólogos adelantan que los triunfadores de mañana serán aquellos que se adapten a los cambios con mayor rapidez y flexibilidad. Frente a la especialización existirá también una demanda de "generalistas", personas capaces de funcionar en varios y diferentes puestos.

\section{FUTURAS PROFESIONES}

Así como algunas profesiones de hoy se extinguirán; según sostiene Keniche Ohmae, aparecerán otras que cubrirán las nuevas necesidades, entre éstos podemos citar.

- Los ociólogos.- Los "ingenieros de ocio" que ofrecerán opciones para el tiempo libre, un campo que se extienda día a día y tienda al pasatiempo educativo. Aumentará la demanda de especialistas capaces de diseñar y construir parques de atracciones, acuarios, zoológicos, museos de ciencia, etc.

- Granjeros marinos.- Los acuicultores estarán a cargo de "ranchos sumergidos" en los que cultivarán y criarán distintas especies de animales y vegetales para el consumo.

- Tecnoagricultores.- Los agricultores del futuro utilizarán robots para el sembrado, tratamiento químico y recolección de las plantas; emplearán equipos de "riego inteligente" que adecuarán la humedad a las necesidades de los vegetales y dispondrán de las PC conectadas a grandes redes de información agrícola.

- Biotecnólogos.- Especialistas en ingeniería genética, gracias a la alta tecnología adaptarán tipos de cereales que podrán crecer en el desierto y ser regados con agua de mar. Multiplicarán animales, vegetales para el consumo humano mediante la clonación. 
Y asimismo aparecerán muchos otras profesiones y oficios que hoy ni siquiera podemos imaginar.

El marketing para el siglo XXI, con las características que ya se han descrito, desarrollará estrategias básicas para la adecuación de nuevas profesiones a las nuevas necesidades de los usuarios y consumidores del futuro.

\section{RETENER A LOS CLIENTES}

Las empresas para retener a sus clientes tienen que hacer un mejor trabajo a través de métodos imaginativos. Para los competidores es cada vez más difícil encontrar nuevos consumidores o usuarios, por lo que está obligando a invertir mayor tiempo posible en imaginar cómo vender más productos y servicios a sus consumidores existentes.

Las empresas se están concentrando en desarrollar la participación del consumidor, más que la participación en el mercado. Están concentrando su atención en los clientes, productos, planeando paquetes de premios para sus clientes más lucrativos; en otras palabras, se puede concluir que las compañías han pasado de una perspectiva de transacción a una perspectiva de desarrollo de la lealtad del consumidor.

\section{BIBLIOGRAFÍA}

AIC

1998. En Revista: Interamérica

Año 1, No 3. Estados Unidos.

BARRÓN ARAOZ, Ricardo

1995."Marketing". Editorial Herrera, Lima.

DIARIOELCOMERCIO

Sección Negocios

DRUCKER,Peter

"Sociedad post capitalista". Normas S. A.

DRUCKER, Peter

1999. "El gran poder de las pequeñas ideas"

Editorial Sudamericana, Buenos Aires - Argentina.

KOTLER, Philip

1997. "Seminarium", Lima.

KOTLER, Philip 1999. "El marketing según Kotker". Paidos Buenos Aires - Argentina.

LOVELOCK, Christopher H. 1999. "Mercadotecnia de servicios". P H H A. Simón Sehuster, México.

NEWELL, Frederick

1997. "Las nuevas reglas de marketing" Mc. Graw Hill, México. 